\title{
A Bilinear Failure Criterion for Mixed-Mode Delamination
}

REFERENCE: Reeder, J. R., "A Bilinear Failure Criterion for Mixed-Mode Delamination," Composite Materials: Testing and Design (Eleventh Volume), ASTM STP 1206. E. T. Camponeschi. Jr., Ed., American Society for Testing and Materials, Philadelphia, 1993, pp. 303-322.

\begin{abstract}
Many different failure criteria have been suggested for mixed-mode delamination toughness, but few sets of mixed-mode data exist that are consistent over the full range of Mode I opening load to Mode Il shear load range. The mixed-mode bending (MMB) test was used to measure the delamination toughness of a brittle epoxy composite, a state-of-the-art toughened epoxy composite. and a tough thermoplastic composite over the full mixed-mode range. To gain insight into the different failure responses of the different materials, the delamination fracture surfaces were also examined. An evaluation of several failure criteria that have been reported in the literature was performed, and the range of responses modeled by each criterion was analyzed. A bilinear failure criterion was introduced based on a change in the failure mechanism observed from the delamination surfaces. The different criteria were compared to the failure response of the three materials tested. The responses of the two epoxies were best modeled with the new bilinear failure criterion. The failure response of the tough thermoplastic composite could be modeled well with the bilinear criterion but could also be modeled with the more simple linear failure criterion. Since the materials differed in their mixed-mode failure response, mixed-mode delamination testing will be needed to characterize a composite material. This paper presents consistent sets of mixed-mode data. provides a critical evaluation of the mixed-mode failure criteria, and should provide general guidance for selecting an appropriate criterion for other materials.
\end{abstract}

KEYWORDS: composite, mixed-mode delamination, toughness testing, failure criteria

\section{Nomenclature}

a delamination length, $\mathrm{m}$

$b$ specimen width, $m$

$c$ position of applied load on lever, $m$

$c_{k}$ position of gravity load on lever, $m$

$E_{11}$ lamina longitudinal modulus, GPa

$F_{22}$ lamina transverse modulus, GPa

$G_{r}$ total mixed-mode strain energy release rate, $\mathrm{J} / \mathrm{m}^{2}$

$G_{1}$. total mixed-mode fracture toughness, $\mathrm{J} / \mathrm{m}^{2}$

$G_{13}$ lamina transverse shear modulus, $\mathrm{GPa}$

$G_{1}$ Mode 1 strain energy release rate, $\mathrm{J} / \mathrm{m}^{2}$

$G_{\mathrm{Ic}}$ pure Mode I fracture toughness, $\mathrm{J} / \mathrm{m}^{2}$

$G_{\mathrm{lc}}^{\mathrm{m}} \quad$ Mode I component of mixed-mode fracture toughness, $\mathrm{J} / \mathrm{m}^{2}$

$G_{\text {II }}$ Mode II strain energy release rate, $\mathrm{J} / \mathrm{m}^{2}$

$G_{1 \mathrm{k}}$ pure Mode II fracture toughness, $\mathrm{J} / \mathrm{m}^{2}$

$G_{\mathrm{llc}}^{m} \quad$ Mode II component of mixed-mode fracture toughness, $\mathrm{J} / \mathrm{m}^{2}$

$h$ specimen half-thickness, $m$

\footnotetext{
'Research engineer, Mechanies of Materials Branch. NASA Langley Research Center, Hampton, VA 23665 5225 .
} 
$I$ bending moment of inertia of specimen half-thickness, $\mathrm{m}^{4}$

$i$ mode interaction parameter

$K_{\mathrm{I}}$ Mode I component of stress intensity factor

$K_{\mathrm{II}}$ Mode II component of stress intensity factor

$L$ specimen half span length, $\mathrm{m}$

$N$ hackle angle parameter

$P_{c} \quad$ critical applied load, $\mathrm{N}$

$\alpha, \beta$ material parameters used in the power law criterion

$\lambda$ elastic foundation parameter, $1 / \mathrm{m}$

$\gamma$ material parameter used in the exponential hackle criterion

$\eta$ material parameter used in the exponential linear $K_{1} / K_{\mathrm{n}}$ criterion

$\kappa, \varphi$ material parameters used in the linear interaction criterion

$\xi, \zeta$ material parameters used in the bilinear criterion

\section{Introduction}

Delamination is a primary failure mode of laminated composite materials. Delamination toughness under Mode I opening load and Mode II shear load can be measured with the double cantilever beam (DCB) test and the end notch flexure (ENF) test, respectively. In structures, however, delaminations are rarely loaded in pure Mode I or pure Mode II but grow under a mixture of Mode I and Mode II loading. Several types of tests have been used to measure mixed-mode delamination fracture toughness. In the past, several different kinds of test specimens were needed to measure delamination fracture toughness over the full range of Mode I and Mode II combinations [1]. Unfortunately it was unclear what effect the different test configurations had on the measured failure response. Recently, however, the mixed-mode bending (MMB) test [2], which simply combines the DCB and ENF loadings, was developed to measure mixed-mode delamination toughness and then redesigned [3] to avoid geometric nonlinearities encountered when testing tough composites. The MMB test allows almost any combination of Mode I and Mode II loading to be tested with the same test specimen configuration. Therefore, inconsistencies present in previous mixed-mode toughness data sets can be avoided.

Many different mixed-mode failure criteria have been suggested for predicting delamination growth, but these criteria were often based on inconsistent sets of toughness data. It is important that accurate mixed-mode failure criteria be developed so that the extension of delaminations in structures can be predicted. Once delamination can be predicted accurately, fewer component and full-scale tests will be required to ensure the safety of composite structures. The purpose of this paper is to evaluate different mixed-mode criteria by comparing them to consistent sets of mixedmode toughness data obtained using the MMB test and also to introduce a bilinear mixed-mode criterion that was developed in the course of this study.

The redesigned MMB test was used to measure the delamination toughness of a brittle epoxy composite, a state-of-the-art toughened epoxy composite, and a tough thermoplastic composite over the full mixed-mode range. The fracture surfaces of the composites were examined to gain insight into the failure responses of the different materials. Next, an evaluation of delamination failure criteria that have been reported in the literature was performed, and the range of material responses modeled by each criterion was evaluated. In addition, a bilinear failure criterion was developed. The failure responses of the three materials were compared to the different mixed-mode failure criteria, and the best criterion for each material was selected.

\section{Toughness Testing}

The redesigned MMB test apparatus was used to measure the mixed-mode delamination toughness of three different composite materials. This test is capable of testing over virtually the entire 
mixed-mode range with consistent test conditions. Consistent sets of data with which to compare proposed failure criteria, therefore, were obtained.

The materials used in this study were chosen to represent a wide range of toughness properties. AS4/3501-6 is a commonly used brittle epoxy composite. IM7/977-2 is a state-of-the-art toughened epoxy composite. It consists of a high-strength IM7 fiber and an epoxy matrix that has been loughened with a thermoplastic additive. The AS4/PEEK (polyether-ether-ketone) is a tough graphite/thermoplastic composite and therefore radically different from the thermoset epoxies. The elastic properties of these three materials are listed in Table 1 . These properties were used in the calculation of fracture toughness. Because the toughness calcuation is very sensitive to the longitudinal modulus $E_{11}$, it was measured using a three-point bend test with a 3 -in. $(7.6-\mathrm{cm})$ span length. $E_{11}$ was measured in bending because a flexurally measured modulus for laminated composite materials has been shown to differ significantly from an axially measured modulus $[4]$, and the MMB test is a bending type of test. The toughness calculation is not as sensitive to the transverse modulus $E_{22}$ and shear modulus $G_{13}$. Therefore, these properties were obtained from the literature $[3,5,6]$.

The materials were made into 24 -ply unidirectional panels. The panels were cut into test specimens that were $1.5 \mathrm{~cm}$ long, $2.54 \mathrm{~cm}$ wide, $b$, and nominally $3 \mathrm{~mm}$ thick, $2 h(6 \mathrm{in.}, 1 \mathrm{in}$. .. and 0.12 in., respectively). Each specimen contained a $0.13-\mu \mathrm{m}(0.5$ mil) thick insert at the midplane of the speciment to act as a delamination starter. A Tefon insert was used in the epoxy specimens while a Kapton insert was used in the PEEK specimens. Loading hinges were bonded to the specimen, shown in Fig. 1 , so that the starter provided a $2.5-\mathrm{cm}(1$-in. $)$ initial delamination length $a$.

TABLE 1-Material properties.

\begin{tabular}{|c|c|c|c|c|}
\hline Material & $E_{1}, G P a$ & $\begin{array}{l}E_{11}{ }^{\prime}, \text { GPa (for } \\
\text { comparison) }\end{array}$ & $E_{22}{ }^{n}, \mathrm{GPa}$ & $G_{13}{ }^{n}, \mathrm{GPa}$ \\
\hline AS4/3501-6 & 132 & 145 & 9.7 & 5.9 \\
\hline $1 \mathrm{M} 7 / 977-2$ & 14.3 & 142 & 9.2 & 4.8 \\
\hline AS4/PEIK (APC2) & 129 & 129 & 10.1 & 5.5 \\
\hline
\end{tabular}

Measured in current study.

Obtained from Refs 3, 5, and 6 .

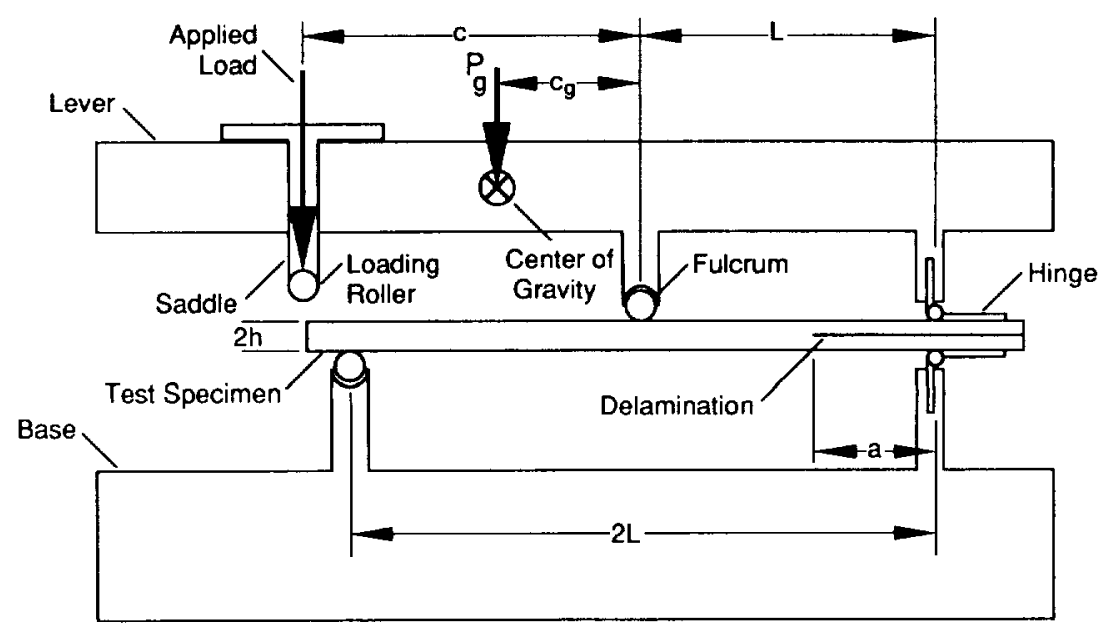

FIG. I The redesigned mixed-mode bending test apparatus. 
The redesigned MMB test apparatus shown in Fig. 1 uses a lever to apply Mode I and Mode II loadings to a split beam specimen. The load on the top hinge tends to pull the delamination open resulting in Mode I loading similar to that of the DCB test. The load at the fulcrum bends the specimen creating a Mode II loading similar to the ENF test. The ratio of the Mode I to Mode II loading is controlled by the lever load position, $c$. The value of $c$ therefore determines the mixedmode ratio $G_{\mathrm{V}} / G_{\mathrm{II}}$. The redesigned apparatus uses a saddle mechanism to hold the loading rollers just above the specimen midplane and on either side of the test specimen. This configuration has been shown to drastically reduce geometric nonlinearity errors that can develop when testing tough materials [3]. The half span length, $L$, of the MMB apparatus was $5.1 \mathrm{~cm}(2 \mathrm{in}$.).

Each material was tested in at least three mixed-mode ratios $\left(G_{\mathrm{l}} / G_{\mathrm{II}}\right)$ and at the two pure-mode cases. The three mixed-mode ratios tested were the $4 / 1,1 / 1$, and $1 / 4$ cases which corresponded to $c$ values of $97.3 \mathrm{~mm}, 42.2 \mathrm{~mm}$, and $27.7 \mathrm{~mm}$, respectively $(3.83 \mathrm{in}$., $1.66 \mathrm{in}$., and $1.09 \mathrm{in}$., respectively). The AS4/3501-6 material was also tested at a $1 / 20$ ratio with a $c$ value $21.6 \mathrm{~mm}(0.85$ in.) while the IM7/977-2 material was tested at the $1 / 2$ ratio with a $c$ value of $33.0 \mathrm{~mm}$ (1.30 in.). The pure Mode I toughness was tested using a standard DCB configuration. The pure Mode II toughness was tested using the MMB apparatus with a $c$ value of 0 . This is equivalent to an ENF configuration. (All the tests are consistent since the mixed-mode test is simply a combination of the pure-mode tests.) Five tests at each test configuration were performed on the epoxies while only three tests were performed for the PEEK material.

The specimens were loaded in displacement control at a rate of $0.5 \mathrm{~mm} / \mathrm{min}(0.02 \mathrm{in} . / \mathrm{min})$ at the lever loading point. The load-displacement response was recorded, and the critical load $P_{c}$ used in $G$ calculations was taken as the load where the load-displacement curve deviated from a linear response. The tests on the epoxy specimen measured the toughness required for delamination to initiate from the insert. The PEEK specimens which were tested in a previous study [3] were first precracked under a $4 / 1$ mixed-mode loading to a delamination length $a$ of $3.2 \mathrm{~cm}$ (1.25 in.) and then tested. Although Murri et al. [7] showed that delamination toughness measured from a precrack could be significantly different from values measured from an insert, a study involving a $4 / 1$ type precrack showed good agreement with insert initiation values [8]. The PEEK toughnesses presented here is slightly lower than that given in Ref 3 because those data were calculated with $P_{\text {, }}$ equal to the maximum applied load. In this study, the edge of the specimen was coated with a white water soluble typewriter correction fluid so that the delamination could be observed more easily with a $7 \times$ magnifying scope. The delamination extension was observed at approximately the same time as the nonlinearity in the loading curve. The delamination length, $a$, was determined by breaking the test specimen open after the test and measuring the length of the initial delamination. For the epoxy specimen this was the length of the insert, while for the PEEK specimen, $a$ was the length to the visible marking on the fracture surface left by the precrack.

The Mode I and Mode II components of fracture toughness, $G_{\mathrm{lc}}^{m}$ and $G_{\mathrm{llc}}^{m}$, were calculated for the IM7/977-2 and AS4/PEEK specimens using the following equations

$$
\begin{aligned}
& G_{\mathrm{lc}}^{m}=\frac{\left(36 c^{2}-24 c L+4 L^{2}\right) P_{c}^{2}}{64 L^{2} b E_{11} l}\left[a^{2}+\frac{2 a}{\lambda}+\frac{1}{\lambda^{2}}+\frac{h^{2} E_{11}}{10 G_{1,3}}\right] \\
& G_{\mathrm{llc}}^{m}=\frac{\left(3 c^{2}+6 c L+3 L^{2}\right) P_{c}^{2}}{64 L^{2} b E_{11} l}\left[a^{2}+\frac{h^{2} E_{11}}{5 G_{13}}\right]
\end{aligned}
$$

where

$$
\lambda=\frac{1}{h} \sqrt[4]{\frac{6 E_{22}}{E_{11}}} \text { and } I=\frac{b h^{3}}{12}
$$


These equations are based on beam theory and include corrections to account for shear deformation and deformation due to the rotation of the specimen cross-section at the delamination tip [2].

The calculation of fracture toughness for the AS4/3501-6 material was more complicated because this material has a lower toughness than the other materials. The weight of the MMB lever has been shown to cause significant errors when testing lower toughness materials [9]. The lever of the redesigned MMB apparatus used in this study was found to weigh $8.23 \mathrm{~N}(1.85 \mathrm{lb})$. The weight of the saddle mechanism contributes to the force $P_{g}$. Since the saddle mechanism is moved when the lever load point is changed, the center of gravity of the lever assembly given by length $c_{g}$ also changes. The relationship between $c$ and $c_{g}$ was found for this apparatus to be $c_{g}=9.65+0.24 c$ where $c$ and $c_{g}$ are expressed in millimeters. The maximum errors were given as $[9]$

$$
\begin{aligned}
& \text { Max \% Error } G_{\mathrm{lc}}^{m} \approx 1.3\left(\frac{c_{g}}{L}-\frac{1}{3}\right) \frac{a P_{g}}{\sqrt{G_{\mathrm{lc}} b E_{1 \mathrm{l}} l}} \times 100 \\
& \operatorname{Max} \% \text { Error } G_{\mathrm{llc}}^{\mathrm{m}} \approx 0.43\left(\frac{c_{g}}{L}+1\right) \frac{a P_{g}}{\sqrt{G_{\mathrm{llc}} b E_{1 \mathrm{l}} I}} \times 100
\end{aligned}
$$

Therefore, the $4 / 1$ mixed-mode case $\left(c=97.3 \mathrm{~mm}\right.$ ) would have a $G_{\mathrm{lc}}$ error of $6 \%$ if the lever weight were neglected. The lever weight was therefore accounted for in all AS4/3501-6 toughness calculations by using the equations [9]

$$
\begin{aligned}
G_{\mathrm{lc}}^{m}= & {\left[\begin{array}{c}
\left(36 c^{2}-24 c L+4 L^{2}\right) P_{c}^{2}+ \\
\left(72 c c_{g}-24 c L-24 c_{g} L+8 L^{2}\right) P_{c} P_{g}+ \\
\left(36 c_{g}^{2}-24 c_{g} L+4 L^{2}\right) P_{g}^{2}
\end{array}\right] \frac{\left[a^{2}+\frac{2 a}{\lambda}+\frac{1}{\lambda^{2}}+\frac{h^{2} E_{11}}{10 G_{13}}\right]}{64 L^{2} b E_{11} \mathrm{I}} } \\
G_{\mathrm{Ilc}}^{m}= & {\left[\begin{array}{c}
\left(3 c^{2}+6 c L+3 L^{2}\right) P_{c}^{2}+ \\
\left(6 c c_{g}+6 c L+6 c_{g} L+6 L^{2}\right) P_{c} P_{g}+ \\
\left(3 c_{g}^{2}+6 c_{g} L+3 L^{2}\right) P_{c}^{2}
\end{array}\right] \frac{\left[a^{2}+\frac{h^{2} E_{11}}{5 G_{13}}\right]}{64 L^{2} b E_{11} \mathrm{I}} }
\end{aligned}
$$

The pure Mode I toughness was calculated using Eq 4 for all materials.

$$
G_{\mathrm{lc}}=\frac{P_{c}^{2}}{b E_{11} \mathrm{I}}\left[a^{2}+\frac{2 a}{\lambda}+\frac{1}{\lambda^{2}}+\frac{h^{2} E_{1 \mathrm{II}}}{10 G_{13}}\right]
$$

This equation was used in developing the mixed-mode equations and is consistent with the mixedmode equations. The pure Mode II toughness $G_{\text {IIc }}$ can be calculated from the equations for $G_{\mathrm{Ilc}}^{\prime \prime}$ in Eqs 1 or 3 where $c$ is set to 0 . Notice that the $G_{1 \mathrm{c}}^{m}$ equations give erroneous results at this $c$ value because for $c \leqslant 1.7 \mathrm{~cm}(0.67 \mathrm{in}$.), the delamination surfaces do not separate allowing load to be transferred across the face of the delamination [2]. This contact force is not modeled by Eqs 1 and 3 and cause the true $G_{\mathrm{lc}}^{m}$ to be 0 but do not effect the $G_{\mathrm{ll}}^{m}$ values.

The delamination fracture surfaces were examined using a scanning electron microscope (SEM). SEM photomicrographs were taken just beyond the delamination insert for the epoxy composites and just beyond the precrack marking for the PEEK composite. Therefore, the fracture surfaces show the first increment of delamination growth which correspond to the measured fracture toughnesses.

\section{Toughness Test Results}

The mixed-mode failure responses of the three composite materials are presented by plotting $G_{\mathrm{L}}^{m}$ versus $G_{\mathrm{IL}}^{m}$. These mixed-mode diagrams are plotted in Fig. 2 . The failure responses of the two 


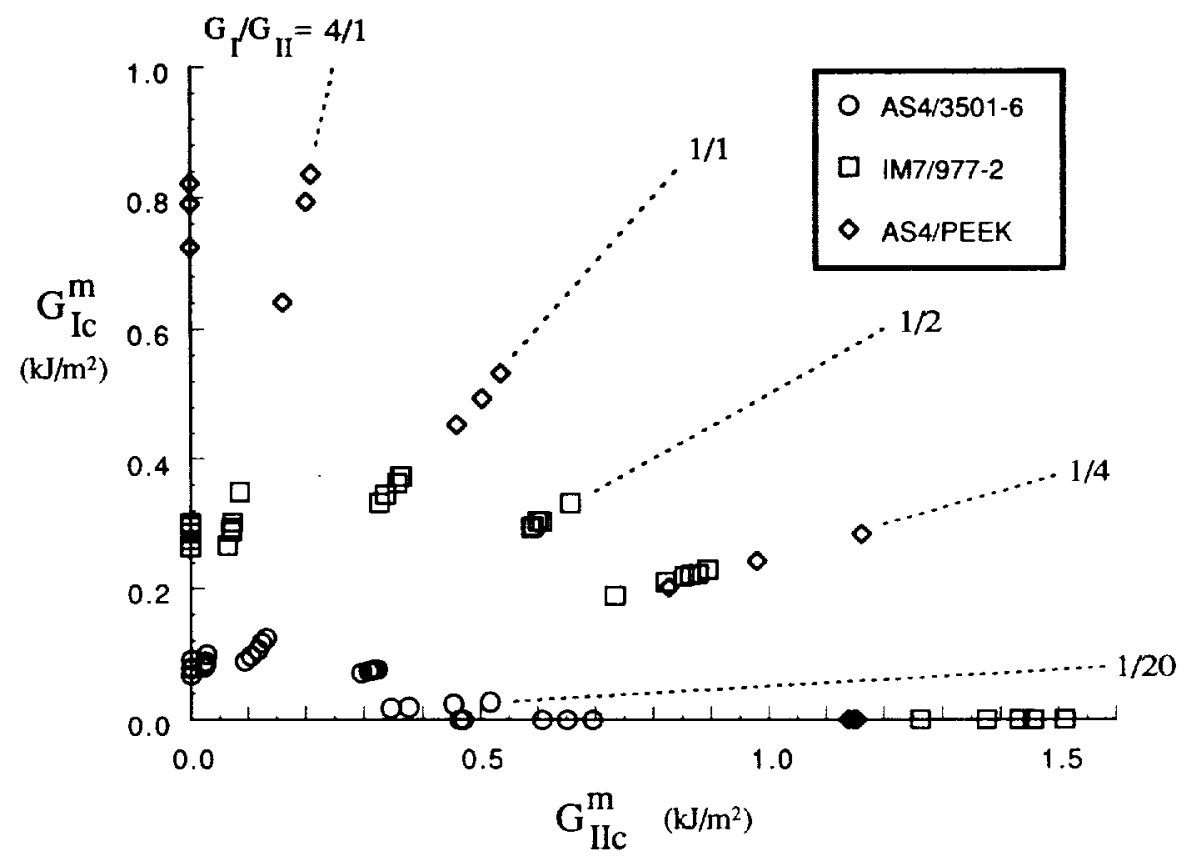

FIG. 2-Mixed-mode failure responses of graphite composite materials $\left(/ \mathrm{kJ} / \mathrm{m}^{2}=5.7 / \mathrm{in}\right.$.$\left(b /\right.$ in. $\left.^{2}\right)$

epoxy composites are quite similar in shape, but the AS4/3501-6 material is more brittle than the IM7/977-2. For both epoxies, the $G_{\mathrm{lc}}^{m}$ values appear to increase as the $G_{1 \mathrm{lc}}^{m}$ is introduced and then slowly decrease to zero as $G_{\mathrm{llc}}^{m}$ approaches $G_{\mathrm{ll}}$. The rising $G_{\mathrm{lc}}^{m}$ with $G_{\mathrm{lc}}^{m}$ may be somewhat surprising, but this phenomenon can also be seen in data presented in Refs $I 0$ and $I I$. The overall shape of the failure response is convex and very similar in shape to the mixed-mode diagram for a brittle-epoxy composite system studied in Ref $I$. The AS4/PEEK material is even tougher than the IM7/977-2 material at all mixed-mode ratios except near pure Mode II, and the shape of the failure response is quite different. $G_{\mathrm{lc}}^{m}$ decreases almost linearly with $G_{\mathrm{llc}}^{m}$ which produces a mixed-mode diagram very similar to those presented in Ref $l$ for different tough composite systems. Since the shapes of the failure responses of the materials are so different, it is clear that no single criterion based on just $G_{\mathrm{lc}}$ and $G_{\mathrm{II}}$ will model all delamination failure. One criterion might be able to model the different materials if material parameters can be changed so that the criterion can be fit to the data. If this approach fails, then different criteria would have to be used for different materials.

SEM photomicrographs show that the fracture surfaces of the different materials change dramatically with mixed-mode ratio. As discussed earlier, these photomicrographs were taken just after delamination initiation. Figure 3 shows the delamination surfaces at different mixed-mode ratios for the AS4/3501-6 composite. The photomicrographs were taken at a magnification of $1000 \times$. At pure Mode $I$ the fracture surface is very flat indicating a brittle cleavage fracture which would explain the low Mode I fracture toughness. As Mode II is added, the fracture surfaces becomes rougher as seen in the $4 / 1$ ratio case. Troughs have appeared where fibers have been pulled away from the matrix indicating interfacial failure. The side of the fracture surface that did not contain a large percentage of fibers is shown here because the texture of the fractured resin is easier to see in this view. The increased roughness, which indicates a more tortuous delamination path, could 


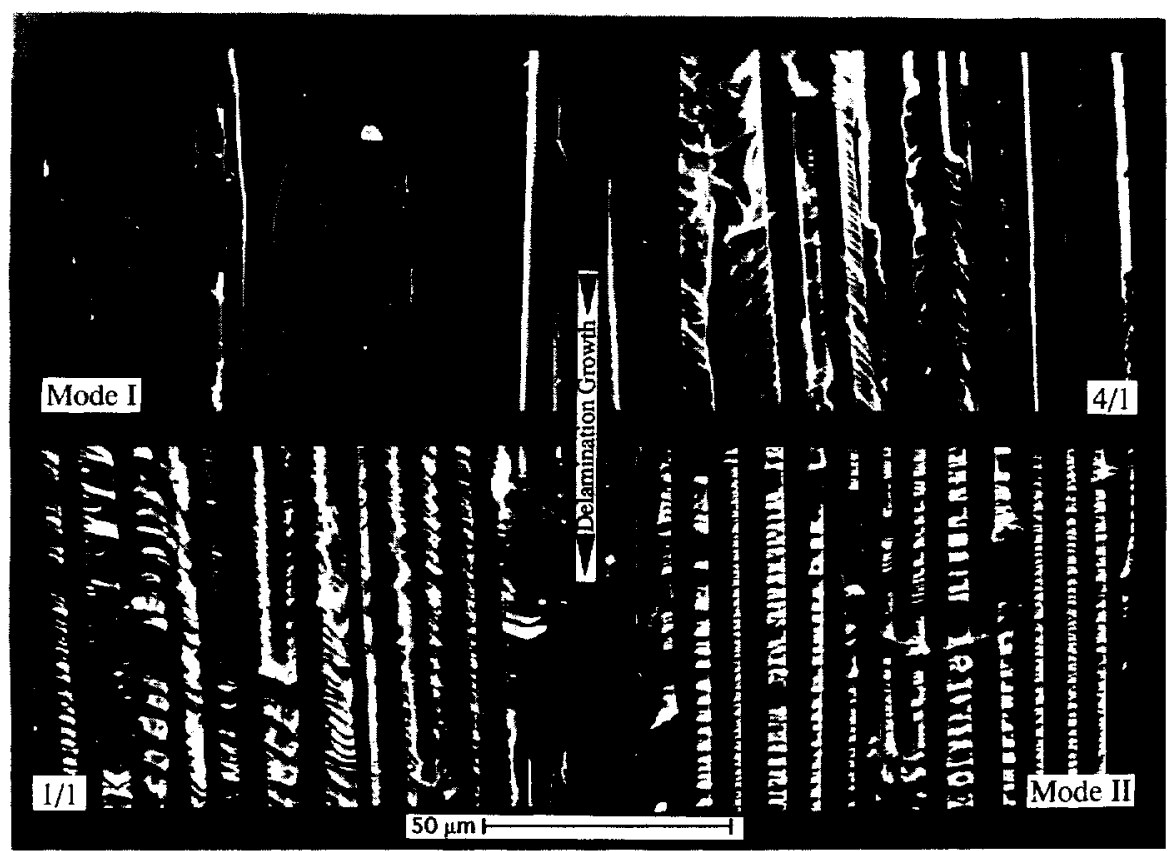

FIG. 3-Delamination photomicrographs of AS4/3501-6 at different mixed-mode ratios $(-1000 \times)$.

explain why the Mode I component of fracture toughness rises as Mode $I 1$ is introduced. The fracture surface at the $1 / 1$ mixed-mode ratio is characterized by hackles. Hackles are features that are "flake-like in appearance and ... overlap on top of one another similar to the shingles on the roof of a house" $|12|$. The pure Mode II fracture surface also contains hackles, and the similarity between the $1 / 1$ and pure Mode II fracture surfaces indicates a single failure mode through this region. The difference between these fracture surfaces and those at the pure Mode I and $4 / 1$ case may indicate a change in the failure mechanism near the $1 / 1$ ratio.

Figure 4 shows the fracture surfaces of the IM7/977-2 composite at several mixed-mode ratios. As seen from the figure, the fracture surfaces of IM7/977-2 are very similar to those of AS4/3501-6. The Mode I fracture is cleavage; fiber troughs appear at the $4 / 1$ ratio; and the hackling begins around the $1 / 1$ ratio and continues through the pure Mode II condition. The change in fracture surface between the $4 / 1$ and $1 / 1$ ratio is even more pronounced for this material than for the AS4/ 3501-6, and again may indicate a changing failure mechanism. The similarity in the fracture surfaces of these materials may explain the similarity between the shapes of the failure responses of these two materials which can be seen in Fig. 2. No explanation for the increased toughness of IM7/ 977-2 over AS4/3501-6 could be made by observing the fracture surfaces at the magnification used in this study.

The fracture surfaces of the PEEK composite shown in Fig. 5 are noticeably different from those of the epoxies. All the PEEK fracture surfaces have cusps caused by the extensive yielding of the matrix. The higher strain to failure created by the yielding gives this material a higher fracture toughness than the epoxies tested. The ridges and valleys seen in the figure are due to the fibers that have been pulled out of the valleys. The ridges form because the larger volume of matrix material found between the fibers can undergo more deformation, thereby creating the ridges of cusps. The 


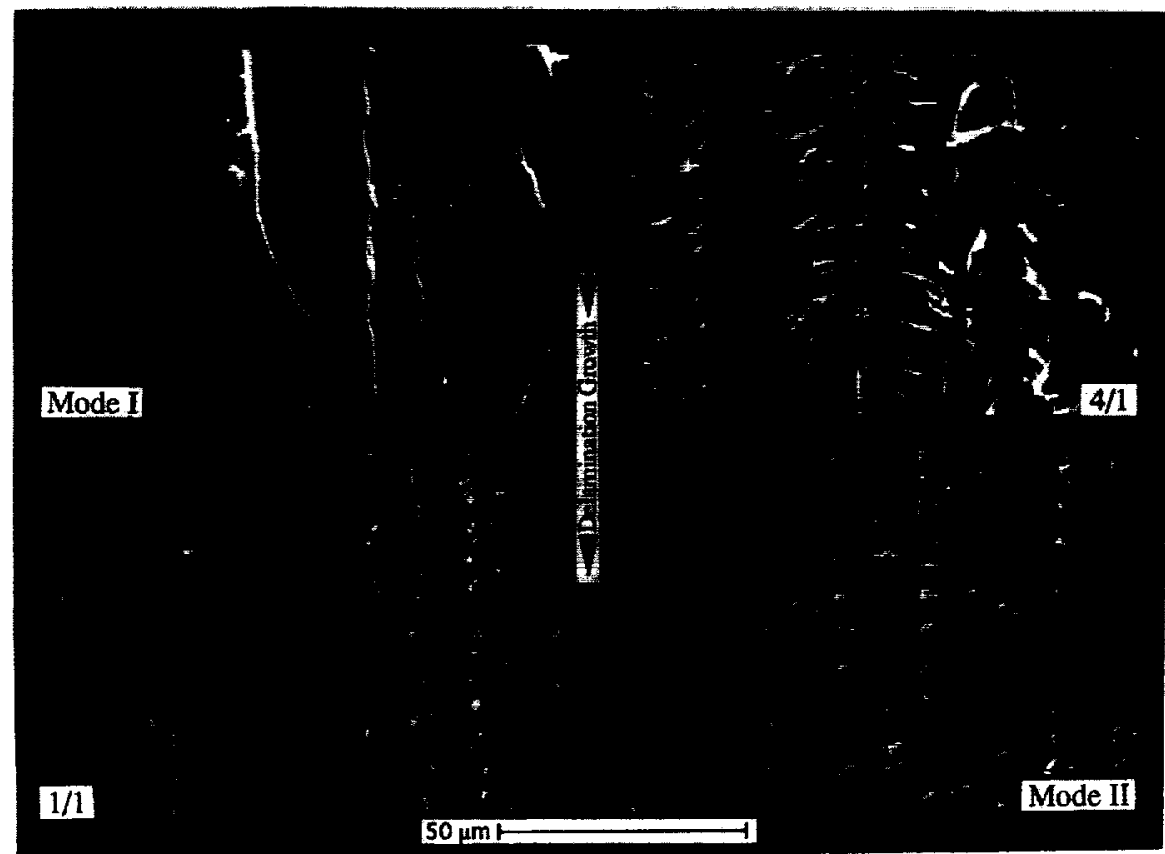

FIG. 4-Delamination photomicrographs of IM7/977-2 at different mixed-mode ratios $(\sim 1000 \times)$.

primary difference between the fracture surfaces at different mixed-mode ratios is the orientation of the cusps. The Mode I fracture surface has cusps that are randomly pulled in different directions. In the $1 / 1$ fracture surface the cusps tend to be drawn slightly toward the top of the micrograph due to the Mode II action. Larger amounts of Mode II draw the cusps more and more, and in the pure Mode II fracture surfaces, all the cusps are extensively drawn upward. No indication of hackling or of changing failure mechanism was observed on the AS4/PEEK fracture surfaces.

\section{Mixed-Mode Delamination Criteria}

Many modeling attempts have been made to describe the mixed-mode delamination failure response of composite materials. Failure criterion have been based on stress or strain near the crack tip, crack opening displacement, stress intensity factor, or strain energy release rate. Strain energy release rate seems to be a good measure of a material's resistance to delamination extension and most of the failure criteria that have been suggested can be written in terms of a critical strain energy release rate or fracture toughness. Although the primary interest in this paper is delamination, criteria suggested for both delamination and ply cracking will be presented. In both ply cracking and delamination, a crack is growing in the matrix in the direction of the fibers. Because the fiber-matrix geometry of both types of cracks are so similar, one would expect the failure responses to be similar as well. In addition to the failure criteria that have been found in the literature, a bilinear failure criterion will be introduced.

The mixed-mode failure criteria will be written in terms of the Mode I and Mode II toughnesses, $G_{\mathrm{lc}}$ and $G_{\mathrm{ll}}$, since pure mode toughness data are readily available. The mixed-mode failure response of a material can be described by plotting the Mode I component of fracture toughness, 


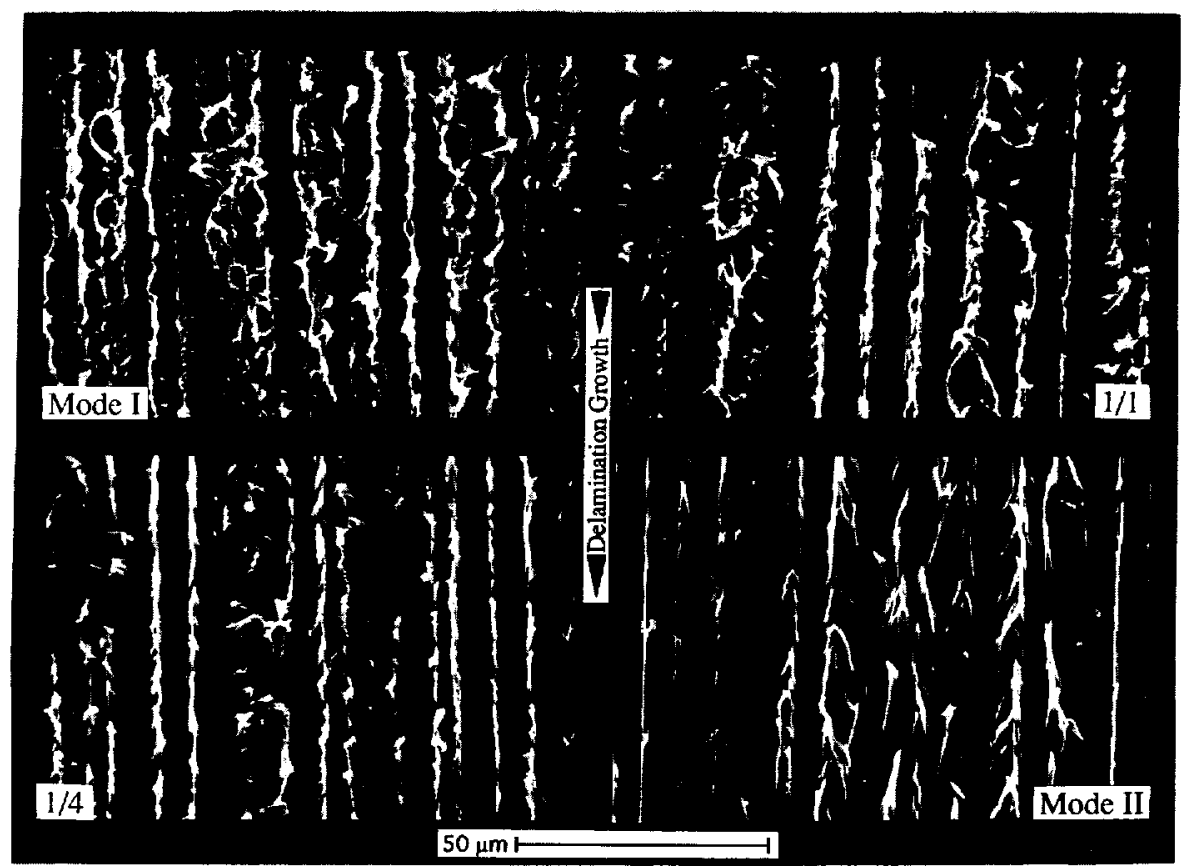

FIG. 5-Delamination photomicrographs of AS4/PEEK at different mixed-mode ratios $(-1000 \times)$.

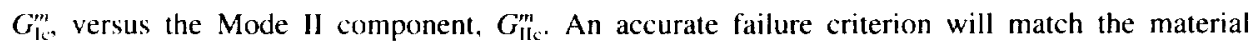
response when plotted on this mixed-mode diagram. Since the response of different materials can be quite different, each failure criterion will be evaluated first by looking at the range of failure responses that each criterion can model. For comparison each criterion will be evaluated assuming $G_{\mathrm{lc}}=1$ and $G_{\mathrm{lk}}=3$. Some criteria also involve the ratio of $E_{1 /} / E_{22}$. For comparison this ratio will be assumed to be 10 . The criteria will be fit to measured toughness data in a subsequent section.

\section{Simple Criteria}

The simplest criteria assume that either the Mode I component [131, the Mode II component [14], or total fracture toughness [15] will stay constant as the mixed-mode ratio changes. These criteria are respectively

$$
\begin{gathered}
G_{\mathrm{lc}}^{m}=G_{\mathrm{lc}} \\
G_{\mathrm{llc}}^{m !}=G_{\mathrm{llc}} \\
G_{\mathrm{lc}}^{m}+G_{\mathrm{llc}}^{m}=G_{\mathrm{lc}}
\end{gathered}
$$

These criteria are plotted on the mixed-mode diagram $\left(G_{1}\right.$ versus $\left.G_{\mathrm{II}}\right)$ in Fig. 6 . The first criterion assumes that only the Mode I component of loading controls delamination growth which therefore assumes that $G_{\mathrm{Il}}$ is insignificant. The second assumes that only the Mode II component of loading is important and therefore that $G_{\mathrm{kc}}$ is insignificant. A more reasonable criterion would be to combine 


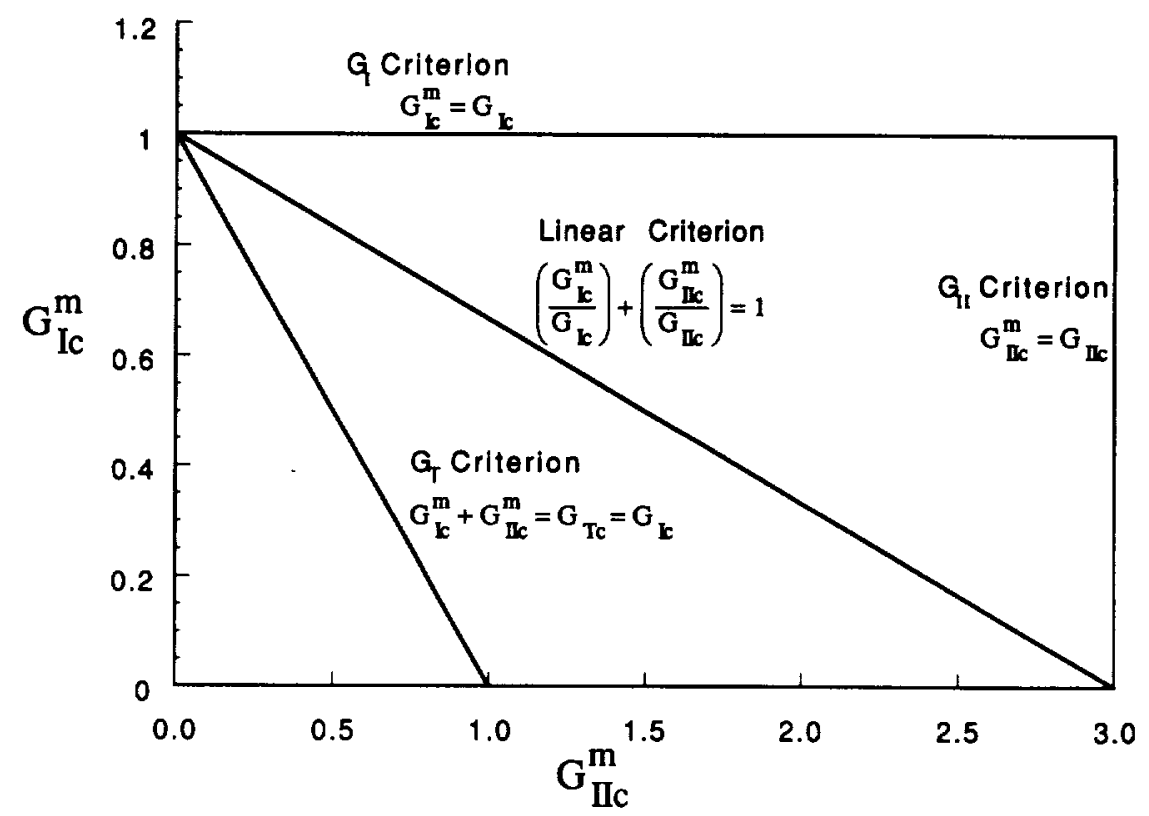

FIG. 6-Mixed-mode fracture toughness diagrams for simple criteria.

the $G_{1}$ and $G_{11}$ criteria (Eqs 5 and 6 ) by assuming that delamination growth would occur if either Eq 5 or 6 is met. This criterion then models the assumption that the Mode I and Mode II failure processes occur independently of each other. The third criterion assumes that a delamination will extend if the total strain energy $G_{\mathrm{T}}$ reaches some critical value $G_{\mathrm{T}_{\mathrm{C}} \text {. The fracture toughness is }}$ assumed not to be a function of mixed-mode ratio which means that $G_{\mathrm{lc}}$ should equal $G_{\mathrm{Ilc}}$. Since $G_{\mathrm{lc}}$ and $G_{\mathrm{IIc}}$ are known to be quite different for most materials, the $G_{\mathrm{T}}$ criterion (Eq 7) was modified to account for materials with different Mode I and Mode II toughnesses as seen in the next criterion.

\section{Linear Criterion}

The fourth criterion simply normalizes each component of fracture toughness by its pure-mode value as given by $|15|$

$$
\left(\frac{G_{\mathrm{lc}}^{\prime \prime}}{G_{\mathrm{Ic}}}\right)+\left(\frac{G_{\mathrm{Ilc}}^{\prime \prime}}{G_{\mathrm{IIc}}}\right)=1
$$

The resulting curve on the mixed-mode fracture toughness diagram is a line connecting the pure Mode I and pure Mode II fracture toughnesses as shown on Fig. 6. This linear criterion (Eq 8 ) is perhaps the mixed-mode criterion most often referred to in the literature $[1,11,16-18]$.

\section{Power Lau' Criterion}

A fifth criterion is obtained by generalizing the linear criterion (Eq 8 ) as a power law function [13] as follows

$$
\left(\frac{G_{\mathrm{lc}}^{m}}{G_{\mathrm{lc}}}\right)^{\alpha}+\left(\frac{G_{\mathrm{llc}}^{m}}{G_{\mathrm{IIc}}}\right)^{\beta}=1
$$




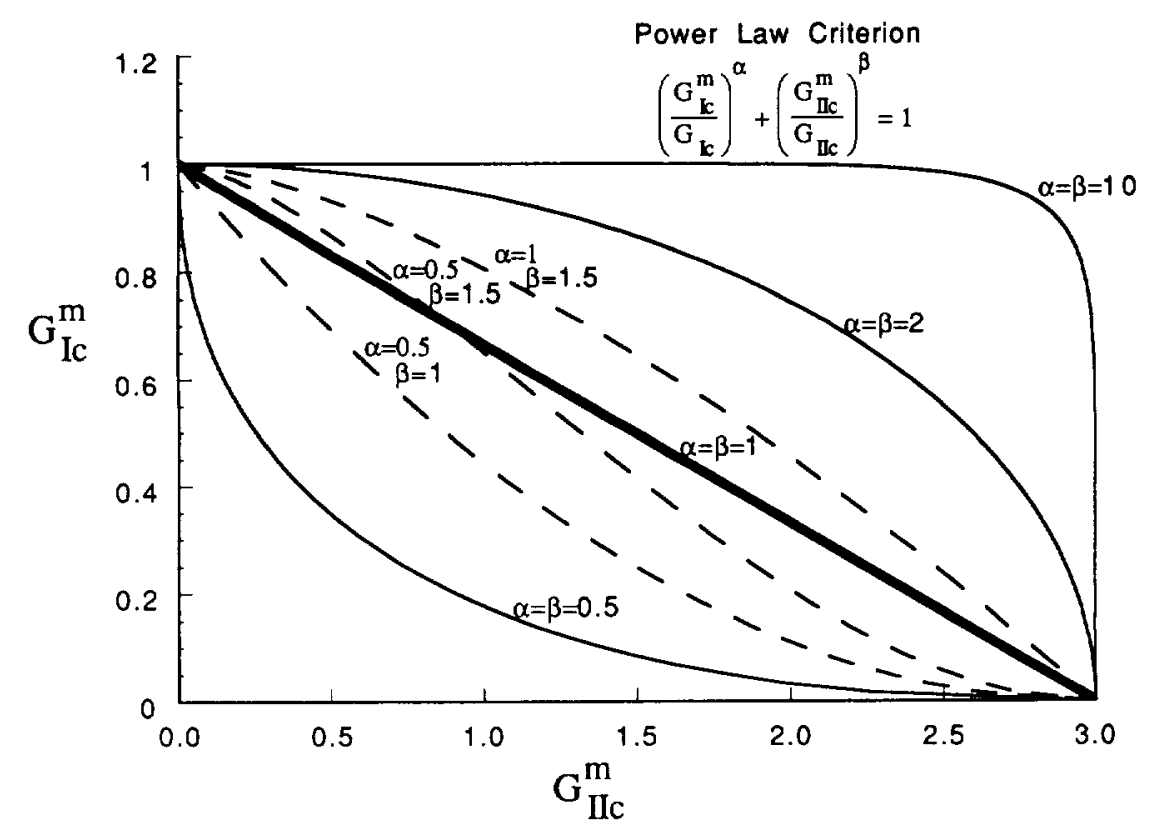

FIG. 7-Mixed-mode fracture toughness diagram for the power law criterion (Eq 9).

By choosing $\alpha$ and $\beta$, a wide range of material responses can be modeled as shown in Fig. 7. When $\alpha=\beta>1$ the failure curve is convex while when $\alpha=\beta<1$ the curve is concave. If $\beta>\alpha$ then the curve is skewed so that the curve is more convex near the Mode I axis. Besides $\alpha=\beta=1$ which reproduces the linear criterion $(\mathrm{Eq} 8)$ several $(\alpha, \beta)$ combinations have been used such as (2.2) [19], $(0.5,1)[15],(1,1.5)[20],(1.4,1.8)[21]$, and (.64,.8) [2I]. An optimum value of $\alpha$ and $\beta$ for a given material can be found by fitting the parameters to experimental data.

\section{Exponential Hackle Criterion}

The next criterion was developed by modeling delamination growth through hackle formation [22]. This criterion was based on an exponential function of the hackle angle parameter $N$. The exponential hackle criterion ( $\mathrm{Eq} 10$ ) was originally written in terms of stress intensity factors but has been written here in terms of strain energy release rate. The exponential hackle criterion is a function of the pure-mode toughnesses, moduli, and only one additional material parameter $\gamma$.

$$
G_{\mathrm{lc}}^{m}+G_{\mathrm{llc}}^{m}=\left(G_{1 \mathrm{c}}-G_{1 \mathrm{lc}}\right) e^{x / l^{\prime}}+G_{\mathrm{llc}} N=\sqrt{1+\frac{G_{\mathrm{llc}}^{m}}{G_{\mathrm{lc}}^{m}} \sqrt{\frac{E_{11}}{E_{22}}}}
$$

The $y$ parameter can be chosen to model a great variety of material responses as shown in Fig. 8 . The exponential hackle criterion can produce a concave or a convex failure envelope and is the first criterion presented which can model an increasing $G_{\mathrm{lc}}^{\prime \prime}$ with increasing $G_{\mathrm{ll}}^{m}$.

\section{Exponential $K_{1} / K_{11}$ Criterion}

Another mixed-mode criterion was based on an exponential function of the mixed-mode stress intensity factor ratio $[23] K_{\mathrm{l}} / K_{11}$. The criterion has been written here in terms of strain energy release rates and the material parameter $\eta$. 


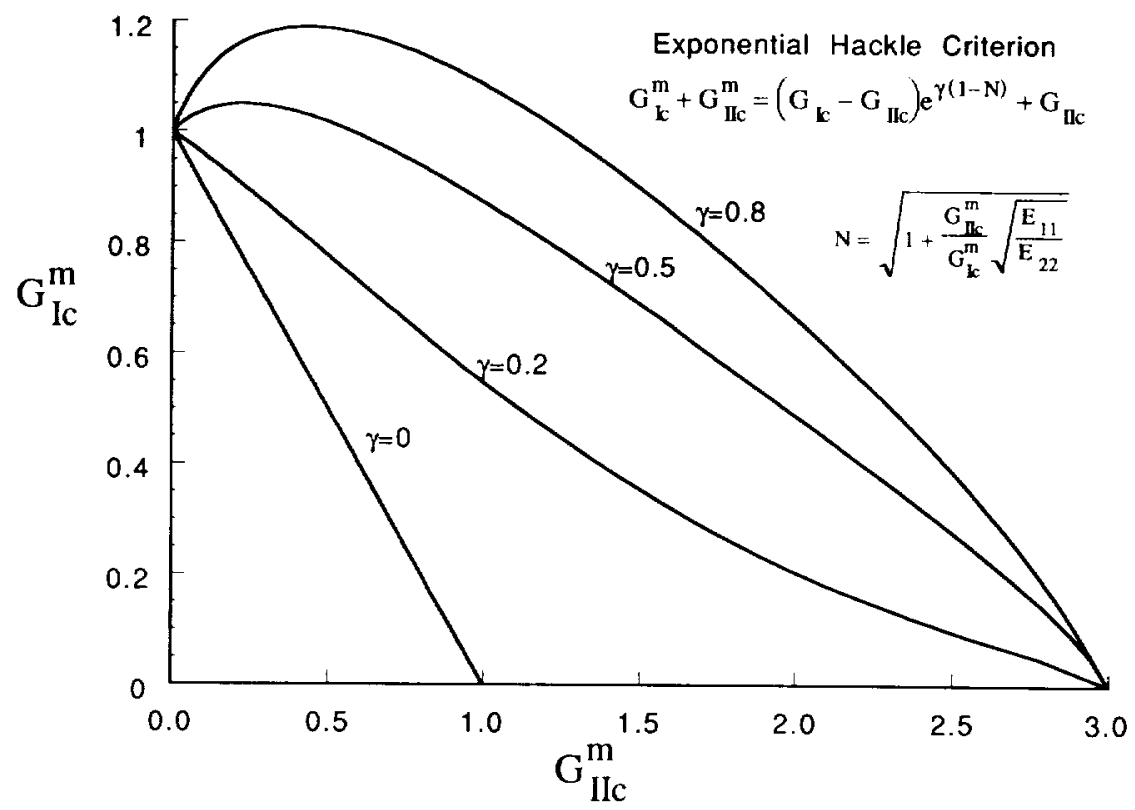

FIG. 8-Mixed-mode fracture foughness diagram for the exponential hackle criterion (Eq 10$)$.

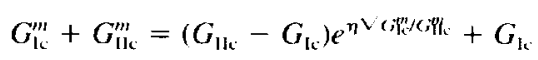

The exponential $K_{\mathrm{I}} / K_{\mathrm{II}}$ criterion (Eq 11 ) is plotted on the mixed-mode diagram in Fig. 9. This criterion can model the same types of responses modeled by the exponential hackle criterion (Eq 10 ), but an abrupt inflection in the failure curve near the Mode I axis is introduced for $\eta \leq 1$.

\section{Interaction Criterion}

Another criterion was developed based on a Mode I-Mode II interaction. The interaction parameter is allowed to vary linearly with the mixed-mode ratio as given by [24]

$$
\left(\frac{G_{\mathrm{lc}}^{m}}{G_{\mathrm{lc}}}-1\right)\left(\frac{G_{\mathrm{llc}}^{m}}{G_{\mathrm{llc}}}-1\right)-i\left(\frac{G_{\mathrm{lc}}^{m}}{G_{\mathrm{lc}}}\right)\left(\frac{G_{\mathrm{llc}}^{m}}{G_{\mathrm{llc}}}\right)=0 \quad i=\left[\kappa+\varphi\left(\frac{G_{\mathrm{lc}}^{m}}{G_{\mathrm{lc}}^{m}+G_{\mathrm{llc}}^{m}}\right)\right]
$$

The larger the magnitude of $i$ the more one mode affects the other. The interaction criterion (Eq 12) can model an increasing Mode I with Mode II as seen in Fig. 10. The following values for $(\kappa, \varphi)$ have been suggested for different materials: $(0.26,0)[25],(3.12,0)[25],(3,-4)|24|$, and $(4,-3)$ [24]. The interaction criterion is a rather complicated implicit function of $G_{\mathrm{Ic}}$ and $G_{\text {IIC }}$ which could make this criterion difficult to use.

\section{New Bilinear Criterion}

This paper introduces a bilinear mixed-mode failure criterion. The delamination fracture surfaces suggested that a change in failure mechanism appears to take place in epoxy matrix composites near the $1 / 1$ ratio of $G_{\mathrm{I}} / G_{\mathrm{II}}$. The mixed-mode fracture toughness data of the epoxy composites (Fig. 2) also show a peak at this ratio. If the failure mechanism does change one might expect different 


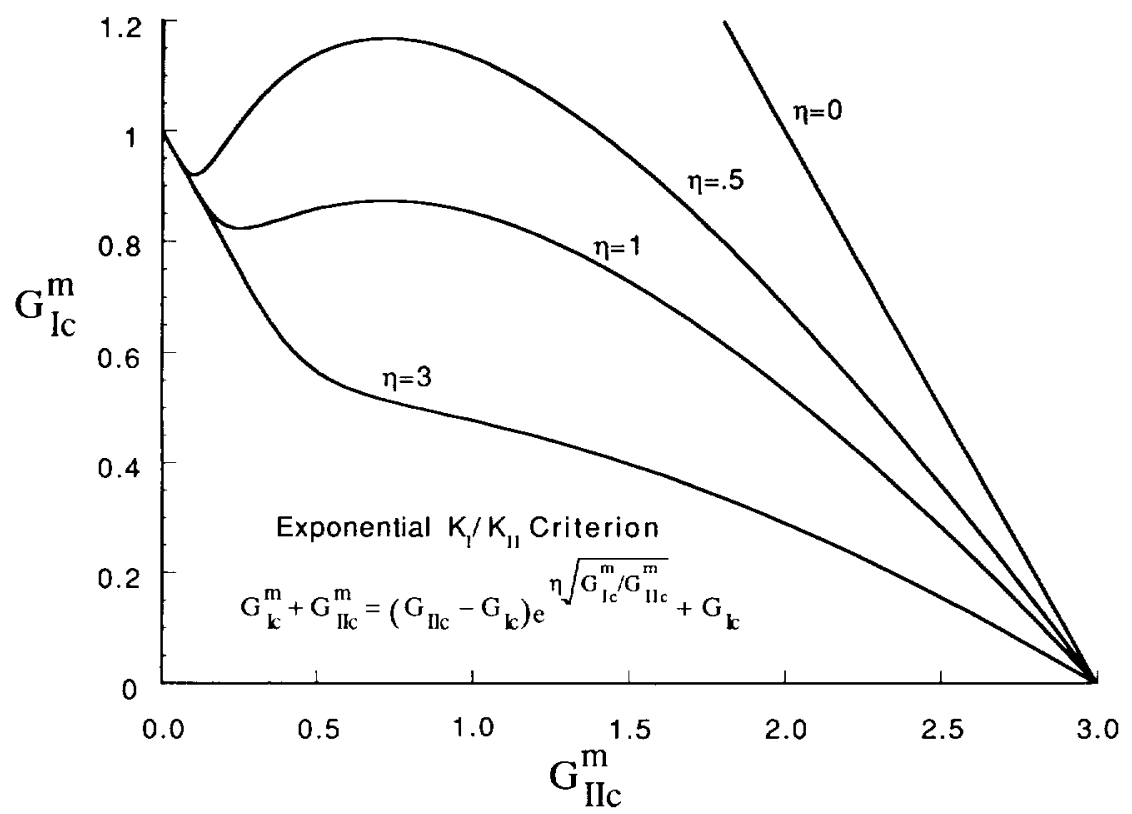

FIG. 9-Mixed-mode fracture toughness diagram for the exponential $K_{\mathrm{V}} / K_{\mathrm{Il}}$ criterion (Eq 11 ).

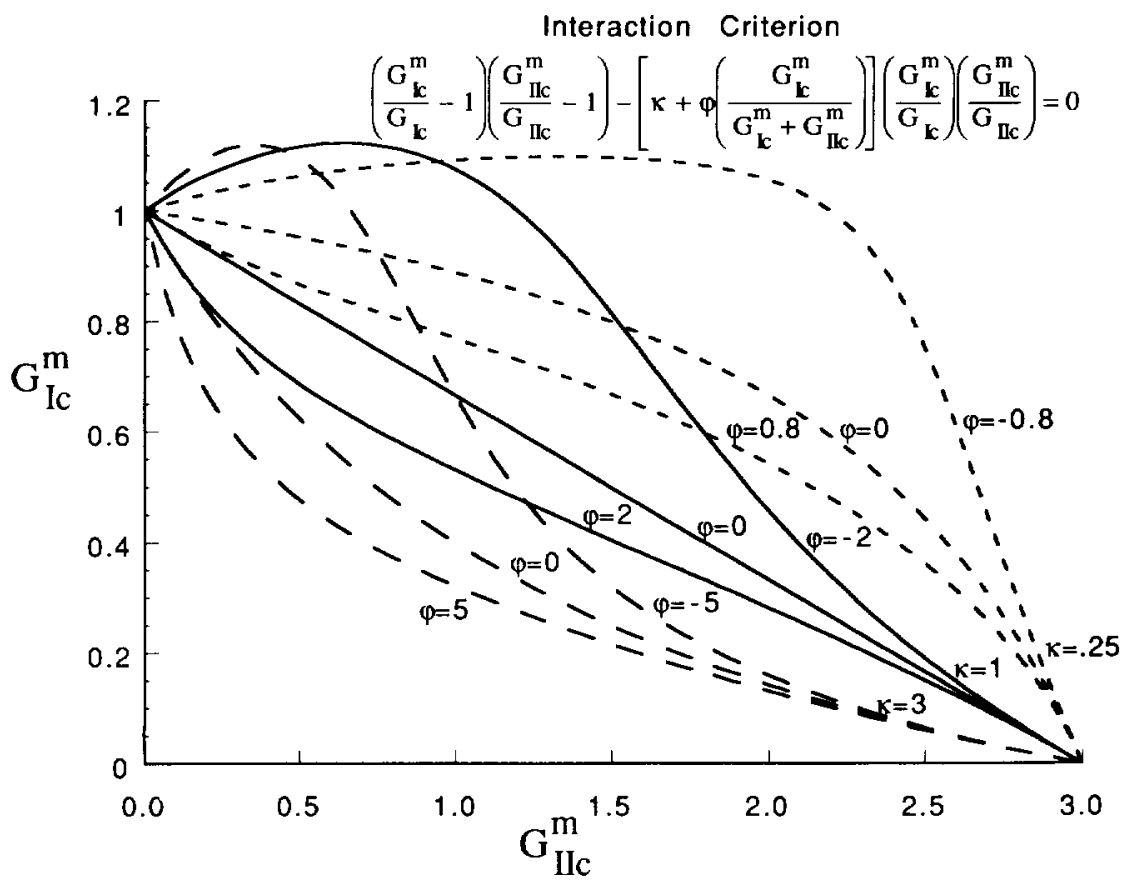

FIG. 10-Mixed-mode fracture toughness diagram for the interaction criterion (Eq 12). 
failure criteria to hold in different regions of the mixed-mode diagram. Shifting from one criterion to another could easily result in a peak in the toughness response as observed in the epoxy composite data around the $1 / 1$ mixed-mode ratio. Since the linear criterion (Eq 8 ) is simple and has seen widespread use. a reasonable assumption would be that the failure response would be linear in each region. The two regions of both the AS4/3501-6 and IM7/977-2 delamination failure data in Fig. 2 do appear rather linear which further supports this assumption. The resulting bilinear failure criterion depends on the material parameters $\xi$ and $\xi$. as well as the two pure-mode loughnesses.

$$
\begin{aligned}
& G_{\mathrm{lc}}^{\prime \prime \prime}=\xi G_{\mathrm{llc}}^{m}+G_{\mathrm{lc}} \\
& G_{\mathrm{lc}}^{m \prime}=\zeta G_{\mathrm{lc}}^{m}-\zeta G_{\mathrm{lc}}
\end{aligned}
$$

$\xi$ and $\zeta$ are the slopes of the two line segments used in the bilinear criterion ( $\mathrm{Eq} 13$ ). As shown in Fig. 11 , this criterion can model concave or convex responses, and it can model an increasing Mode I fracture toughness component with Mode II. If $\xi=\zeta=-G_{1} / G_{1 \mathrm{l}}$, then the bilinear criterion (Eq 13) would reduce to the linear criterion ( $\mathrm{Eq}_{\mathrm{B}} 8$ ).

\section{Other Criterics}

Several other mixed-mode criteria were not evaluated here. They were evaluated previously and were shown to be inadequate models for the material responses presented herein [9]. One criterion assumed that the total fracture toughness would be a polynomial function [26] of the ratio of Mode II to Mode I. Another criterion assumed that the fracture toughness would be a linear function of the Mode I stress intensity factor [27] $K_{\mathrm{l}}$. Yet another criterion [22] assumed delamination growth hased on a linear function of the hackle angle parameter $N$ described earlier. A mixed-mode

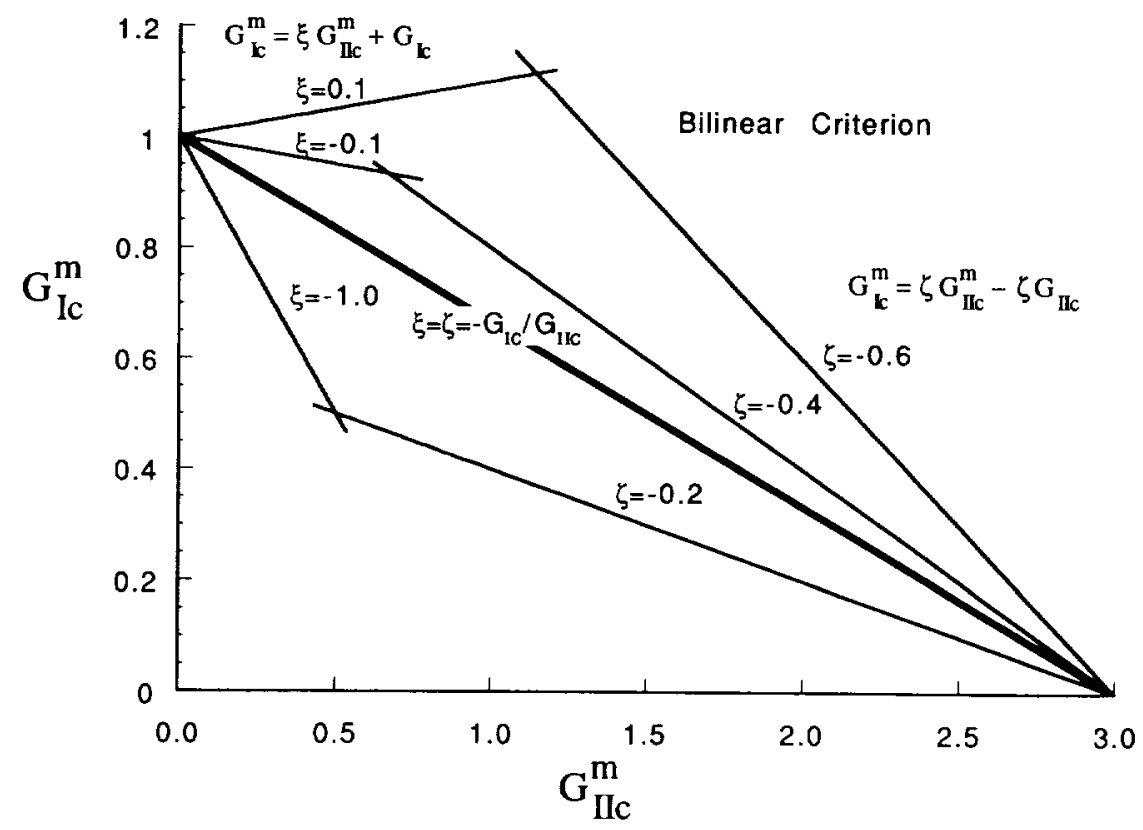

FIG. 11-Mixed-mode fracture toughness diagram for the bilinear criterion (Eq 13). 
criterion based on a critical Mode I or Mode II crack opening displacement [28] (COD) also failed to produce a response similar to those exhibited by the materials presented herein.

\section{Criterion Evaluation}

The fact that so many different mixed-mode criteria have been suggested and used indicate that there is still much to be understood about this phenomenon. The true test of a failure criterion is how well it models the response of the material of interest. In the past, valid data with which to evaluate these criteria did not exist. Little mixed-mode data was available, and those that were available were often obtained from several different tests and were therefore inconsistent. Consistent sets of mixed-mode data for three different materials were presented in Fig. 2. These data sets will be used to evaluate the different criteria.

Each criterion that produced a general shape close to that of one of the material responses was fit to the data. A least squares analysis was performed to optimize the curve fits. The least squares analysis was conducted by minimizing the distance between each data point and the failure curve. The shapes of the failure curves produced by the $G_{\mathrm{Ic}}, G_{\mathrm{IIc}}$, and $G_{\mathrm{Tc}}$ criteria (Eqs 5 through 7 ) are not even close to the material responses observed, so no attempt was made to fit these criteria to the experimental data. Since the shape of the linear criterion (Eq 8 ) was only close to the shape of PEEK data, no attempt was made to use this criterion for either of the epoxies. The power law criterion ( $\mathrm{Eq} 9)$ was fit to each material response even though it cannot model the increasing $G_{\mathrm{lc}}^{\mathrm{m}}$ with $G_{\mathrm{IIc}}^{m}$ observed in the epoxy composite data. The increase in $G_{\mathrm{Ic}}^{m}$ was not large, and failing to model this increase would at least produce a conservative model for the material. The exponential hackle, the exponential $K_{l} / K_{11}$, the interaction, and the bilinear criteria (Eqs 10 through 13) were used to model all three material responses.

The results of the least square fit of each criterion to the experimental data is given in Table 2 . The best fit curves for AS4/3501-6, IM7/977-2, and AS4/PEEK materials response are shown in Figs. 12, 13, and 14, respectively. The interaction criterion ( $\mathrm{Eq} \mathrm{12)} \mathrm{shown} \mathrm{by} \mathrm{the} \mathrm{heavy} \mathrm{dashed} \mathrm{line}$ and the bilinear criterion ( $\mathrm{Eq} 13$ ) shown by the solid line, appear to model the epoxies better than the other criteria. This is also indicated by the coefficients of variation $R^{2}$ given in Table 2 . The closer the coefficient is to 1 the better the model fits the data, and as seen in the table, the interaction and the bilinear criteria (Eqs 12 and 13) produced the coefficients closest to 1 for both AS4/3501-6 and IM7/977-2. The power law criterion (Eq 9) also had a very high $R^{2}$ value for the AS4/3501-6 material, but since the curve does not model the rising $G_{\mathrm{lc}}^{m}$ with $G_{\mathrm{Ic}}^{m}$, the other criteria are believed to be better choices. Both the interaction criterion and the bilinear criterion model the epoxy-based composites well and with the same number of material parameters. The interaction criterion (Eq 12) is a complex implicit function of $G_{\mathrm{lc}}^{m}$ and $G_{\mathrm{llc}}^{m}$ which makes it more difficult to use. The bilinear criterion is based on very simple equations and is therefore easier to use. For this reason the bilinear is believed to be the best choice of failure criteria for these materials.

The PEEK composite was modeled fairly well by all the criteria tested as seen in Fig. 13. The coefficients of variation for this material are all about the same, but they are all noticeably smaller than the coefficients of the other materials because there are fewer experimental points. The power law criterion (Eq 9) produced the smallest coefficient of variation, but the linear criterion (Eq 8 ) produced a curve that was almost as good and with two less independent variables. For this reason, the linear model is believed to be the best failure criterion for this material. Since the bilinear criterion (Eq 13) contains two extra degrees of freedom, it models the PEEK material slightly better than the linear criterion ( $\mathrm{Eq} 8$ ) and might be chosen to be consistent with the criterion used for the epoxy composites.

Because the response of the epoxy composites was quite different from that of the PEEK composite, it is clear that no one failure criterion based on just the pure-mode toughnesses will be able to model all fiber-reinforced polymer composite materials. Since delaminations will often be 
TABLE 2-Least square curve fit parameters for various criteria.

\begin{tabular}{|c|c|c|c|c|c|}
\hline Material & Criterion & $\underset{\mathrm{J} / \mathrm{m}^{2}}{G_{\mathrm{c}}}$ & $\underset{\mathrm{J} / \mathrm{m}^{2}}{G_{1 \mathrm{c}}}$ & Constants & $R^{2}$ \\
\hline \multirow[t]{5}{*}{ AS $4 / 3501-6$} & Power Law (Eq 9) & 90.74 & 698.3 & $\begin{array}{l}\alpha=0.0571 \\
\beta=5.039\end{array}$ & .9956 \\
\hline & Exponential Hackle (Eq 10) & 77.39 & 649.8 & $\gamma=0.1964$ & .9924 \\
\hline & Exponential $K_{1} / K_{\mathrm{II}}(\mathrm{Eq} 11)$ & 90.51 & 541.1 & $\eta=1.664$ & .9888 \\
\hline & Interaction (Eq 12) & 82.95 & 708.8 & $\begin{array}{l}\kappa=1.279 \\
\varphi=-4.905\end{array}$ & .9960 \\
\hline & Bilinear $(\mathrm{Eq} 13)$ & 79.59 & 572.1 & $\begin{array}{l}\xi=0.2039 \\
\zeta=0.2473\end{array}$ & .9956 \\
\hline \multirow[t]{5}{*}{ IM7/977-2 } & Power Law (Eq 9) & 313.6 & 1511 & $\begin{array}{l}\alpha=0.126 \\
\beta=5.447\end{array}$ & .9960 \\
\hline & Exponential Hackle (Eq 10) & 235.4 & 1462 & $\gamma=0.304$ & .9962 \\
\hline & Exponential $K_{\mathrm{l}} / K_{\mathrm{tI}}(\mathrm{Eq}$ il) & 302.8 & 1371 & $\eta=1.050$ & .9948 \\
\hline & Interaction (Eq 12) & 282.8 & 1497 & $\begin{array}{l}\kappa=0.868 \\
\varphi=-2.962\end{array}$ & .9974 \\
\hline & Bilinear (Eq 13) & 283.3 & 1419 & $\begin{array}{l}\xi=0.2107 \\
\zeta=-0.371\end{array}$ & .9976 \\
\hline \multirow[t]{6}{*}{ AS4/PEEK } & Linear (Eq 8) & 830.4 & 1251 & & .9787 \\
\hline & Power Law (Eq 9) & 831.8 & 1164 & $\begin{array}{l}\alpha=1.662 \\
\beta=0.7329\end{array}$ & .9811 \\
\hline & Exponential Hackle (Eq I0) & 794.2 & 1178 & $\gamma=0.8701$ & .9797 \\
\hline & Exponential $K_{1} / K_{\| 1}($ Eq 11) & 789.1 & 1178 & $\eta=0.4940$ & .9799 \\
\hline & Interaction $(\mathrm{Eq} 12)$ & 836.15 & 1179 & $\begin{array}{l}\kappa=0.8679 \\
\varphi=1.058\end{array}$ & .9803 \\
\hline & Bilinear (Eq 13) & 775.8 & 1201 & $\begin{array}{l}\xi=-0.1261 \\
\zeta=-0.7477\end{array}$ & .9801 \\
\hline
\end{tabular}

subjected to mixed-mode loading and because the mixed-mode failure response cannot be determined from the pure-mode toughnesses, it is important that mixed-mode toughness testing be included during the characterization of a material. Once the mixed-mode response of a material has been determined, the shape of the response can be compared to the different failure criteria presented herein. When choosing the best failure criterion for a given material one should consider which criterion has been used successfully for similar materials. It is hoped that a standard choice of failure criteria will emerge for different classes of material such as a linear criterion for thermoplastic composites and a bilinear criterion for epoxy composites. When choosing a failure criterion, one should also consider the number of material parameters and whether the criterion is in a form that can be easily used. A simpler criterion with fewer material parameters is preferred if it models the material as well as a more complicated one. After the appropriate failure criterion for the material is chosen, a least squares fit to the experimental data can be performed to optimize the material parameters of the criterion.

\section{Conclusions}

Many delamination failure criteria that predict a wide variety of mixed-mode fracture toughness responses have been reported in the literature, but few consistent sets of mixed-mode data exist with which to compare these criteria. The mixed-mode bending (MMB) test was used to measure the mixed-mode delamination toughness of a brittle epoxy composite, a state-of-the-art toughened epoxy composite, and a tough thermoplastic composite. The MMB test, which is a combination of 


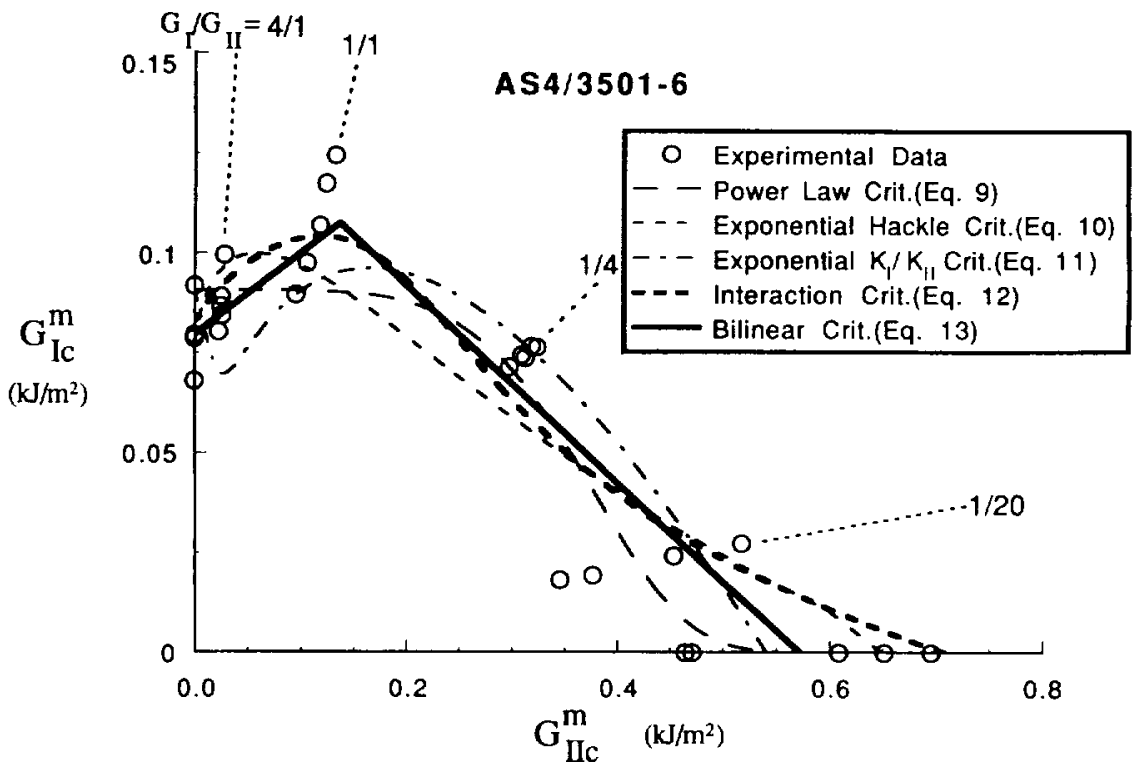

FIG. 12-Mixed-mode toughness criterion curves for AS4/3501-6 $\left(1 \mathrm{~kJ} / \mathrm{m}^{2}=5.7 \mathrm{in} .-\mathrm{lb} / \mathrm{in}^{2}\right)$.

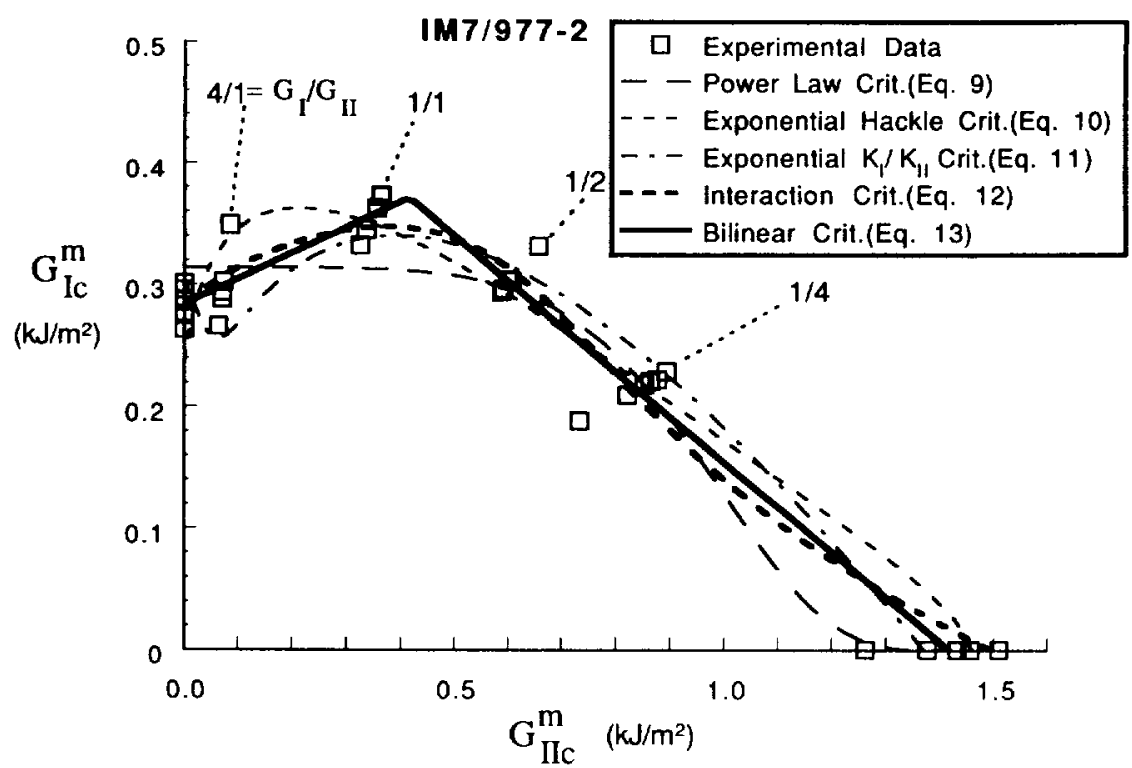

FIG. 13-Mixed-mode toughness criterion curves for 1 M7/977-2 $\left(1 \mathrm{~kJ} / \mathrm{m}^{2}=5.71 \mathrm{in} . \mathrm{-lb} / \mathrm{in} .^{2}\right)$. 


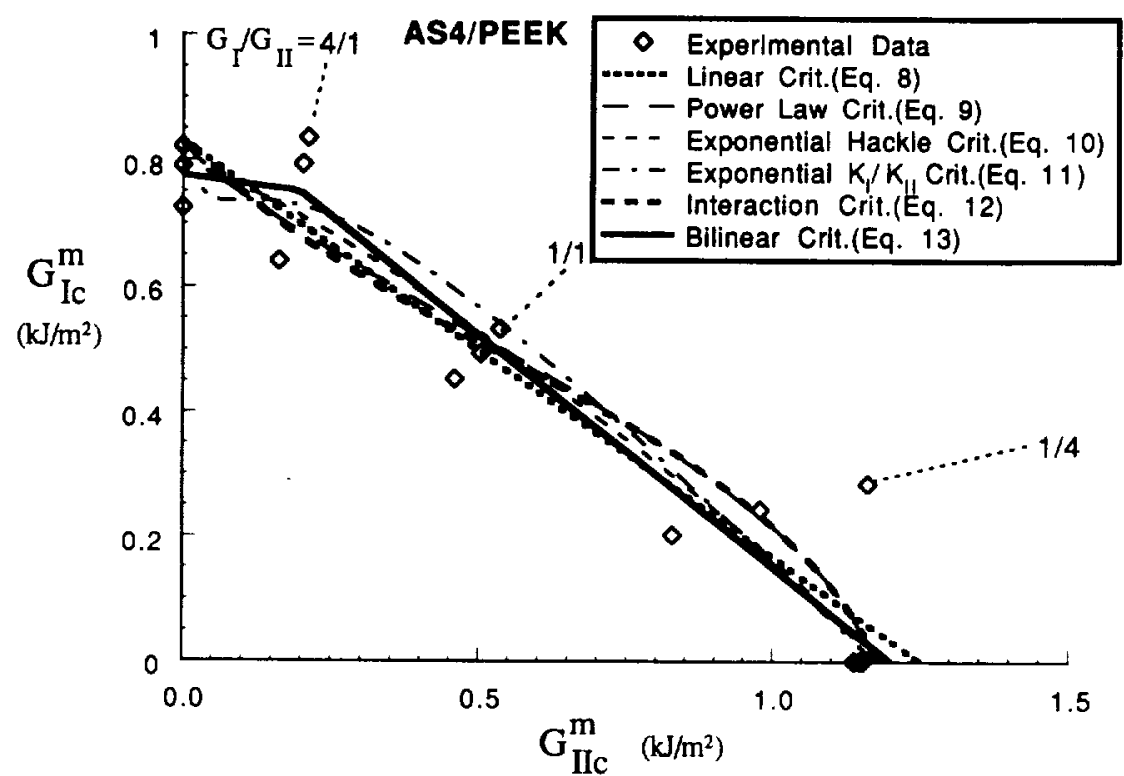

FIG. 14-Mixed-mode toughness criterion curves for AS4/PEEK $\left(I \mathrm{~kJ} / \mathrm{m}^{2}=5.71 \mathrm{in.}-\mathrm{lb} / \mathrm{in}^{2}{ }^{2}\right)$.

the pure Mode I (DCB) test and the pure Mode II (ENF) test, allowed a consistent set of toughness data to be produced across the entire mixed-mode range. The delamination fracture surfaces were examined and a possible change in failure mechanism was observed in the two epoxy composites tested.

Criteria that have been suggested by other investigators were reviewed and the material responses modeled by each criterion were compared to the measured material responses. A bilinear failure criterion was also introduced in an attempt to model the possible change in failure mechanism observed in the epoxy composites. The new bilinear failure criterion modeled the epoxy composites as well as or better than the earlier models and is relatively simple. The failure response of the thermoplastic matrix composite, which did not show signs of a changing failure mode, was quite different from that of the epoxies but could be modeled well with either the bilinear or an even simpler linear criterion.

Since the responses of the epoxy composites were quite different from that of the thermoplastic composite, no one failure criterion based on just the pure-mode toughnesses will be able to model all laminated composite materials. Because delaminations will often be subjected to mixed-mode loading and because the mixed-mode failure response cannot be determined from the pure-mode toughnesses, it is important that mixed-mode toughness testing be included during the characterization of a composite material. Once mixed-mode toughness testing has been conducted the evaluation of the different failure criteria presented in this paper should provide general guidance for selecting the most appropriate failure criterion.

\section{References}

[1] Johnson, W. S. and Mangalgiri. P. D.. "Influence on the Resin on Interlaminar Mixed-Mode Fracture," Toughened Composites, ASTM STP 937. N. J. Johnston, Ed., American Society for Testing and Materials, Philadelphia, 1987, pp. 295-315. 
[2] Reeder, J. R. and Crews, J. H. Jr., "The Mixed-Mode Bending Method for Delamination Testing," AIAA Journal, Vol. 28, No. 7, July 1990, pp. 1270-1276.

[3] Reeder, J. R. and Crews, J. H. Jr., "Redesign of the Mixed-Mode Bending Test for Delamination Toughness," Composites Design, Manufacture, and Application. ICCM/8 Conference Proceedings, SAMPE, July 1991, S. W. Tsai and G. S. Springer, Eds., pp. 36-B-1-36-B-10.

[4] O'Brien, T. K., Murri, G. B., and Salpekar, S. A., "Interlaminar Shear Fracture Toughness and Fatigue Thresholds for Composite Materials," Composite Materials: Fatigue and Fracture, Second Volume. ASTM STP 1012, P. A. Lagace, Ed., American Society for Testing and Materials, Philadelphia, 1989, pp. 222-250.

[5] Hercules Composites Products Group, "Hercules Prepreg Tape Materials Characterization Data Package," Hercules Co., Magna, UT, February 1989.

[6] Smith, D. L. and Dow, M. B., "Properties of Three Graphite/Toughened Resin Composites," NASA TP 3102, September 1991.

[7] Murri, G. B. and Martin, R. H., "Effect of Initial Delamination on Mode I and Mode II Interlaminar Fracture Toughness and Fatigue Fracture Threshold." NASA TM 104079, May 1991.

[8] Crews, J. H. Jr. and Reeder, J. R., "A Mixed-Mode Bending Apparatus for Delamination Testing," NASA TM 100662 , August 1988

[9] Reeder, J. R., "An Evaluation of Mixed-Mode Delamination Failure Criteria," NASA TM 104210, February 1992.

[10] Hibbs, M. F., Tse, M. K., and Bradley, W. L., "Interlaminar Fracture Toughness and Real-Time Fracture Mechanism of Some Toughened Graphite/Epoxy Composites," Toughened Composites, ASTM STP 937. N. J. Johnston, Ed., American Society for Testing and Materials. Philadelphia, 1987. pp. 115-130.

[II] Donaldson, S. L., "Fracture Toughness Testing of Graphite/Epoxy and Graphite/PEEK Composites," Composites, April 1985, pp. 103-109

[12] Morris, G. E., "Determining Fracture Directions and Fracture Origins on Failed Graphite/Epoxy Surfaces," Nondestructive Evaluation and Flaw Criticality for Composite Materials, ASTM STP 696, R. B. Pipes, Ed., American Society for Testing and Materials, Philadelphia, 1979, pp. 274-297.

[13] Whitcomb, J. D., "Analysis of Instability-Related Growth of a Through-Width Delamination," NASA TM 86301 , September 1984

[14] Gillespie, J. W. Jr., Carlsson, L. A., Pipes, B. R., et al., "Delamination Growth in Composite Materials," NASA CR 176416, December 1985

[15] Wu. E. M. and Reuter, R. C. Jr., "Crack Extension in Fiberglass Reinforced Plastics," $T \& A M$ Report No. 275, University of Illinois, 1965.

[16] Spencer, B. and Barnby, J. T., "The Effects of Notch and Fibre Angles on Crack Propagation in FibreReinforced Polymers," Journal of Material Science, Vol. 11, 1976, pp. 83-88.

[I7] Jurf, R. A. and Pipes, R. B., "Interlaminar Fracture of Composite Materials," Journal of Composite Materials, Vol. 16, September 1982, pp. 386-394.

[18] Mall. S. and Kochhar, N. K., "Criterion for Mixed-Mode Fracture in Composite Bonded Joints," NASA CR 1781/2, May 1986.

[19] Ashizawa, M., "Faster Interlaminar Fracture of a Compressively Loaded Composite Containing a Defect," presented at the Fifth DOD/NASA Conference on Fibrous Composites in Structural Design, New Orleans, LA, January 1981 (available as Douglas Paper No. 6994)

[20] Donaldson. S. L.. "The Effect of Interlaminar Fracture Properties on the Delamination Buckling of Composite Laminates," Composite Science and Technology, Vol. 28, 1987, pp. 33-44.

[2I] Hashemi, S., Kinloch, A. J., and Williams, J. G., "Mechanics and Mechanisms of Delamination in a Poly(ether sulphone)-Fibre Composite," Composites Science and Technology, Vol. 37, 1990, pp. $429-462$.

[22] Hahn, H. T. and Johannesson, T., "A Correlation Between Fracture Energy and Fracture Morphology in Mixed-Mode Fracture of Composites," ICM 4, Vol. I, 1983, pp. 431-438.

[23] White, Scott R., "Mixed-Mode Interlaminar Fracture of Graphite/Epoxy Composites," Master's thesis, Washington University, Saint Louis, MO, May 1987.

[24] Hashemi, S., Kinloch, A. J., and Williams, G., "Mixed-Mode Fracture in Fiber-Polymer Composite Laminates," Composite Materials: Fatigue and Fracture, Vol. 3, ASTM STP 1110. T. K. O'Brien, Ed.. American Society for Testing and Materials, Philadelphia, 1991, pp. 143-168.

[25] Hashemi, S., Kinloch, A. J., and Williams, J. G., "The Effects of Geometry, Rate and Temperature on the Mode I. Mode II and Mixed-Mode U/II Interlaminar Fracture on Carbon-Fibre/Poly(ether-ether ketone) Composite." Journal of Composite Materials. Vol. 24, September 1990, pp. 918-956.

[26] Yan, X. Q., Du, S. Y.., and Wang, D., "An Engineering Method of Determining the Delamination Fracture Toughness of Composite Laminates," Engineering Fracture Mechanics, Vol. 39, No. 4, 1991, pp. $623-627$ 
[27] Hahn, H. T., "A Mixed-Mode Fracture Criterion for Composite Materials," Composites Technology Review, Vol. 5, Spring 1983, pp. 26-29.

[28] Hashemi, S., Kinloch, A. J., and Williams, J. G., "Interlaminar Fracture of Composite Materials," oth ICCM \& 2nd ECCM Conference Proceedings, Elsevier Applied Science, London, Vol. 3, July 1987, pp. $3.254-3.264$. 